\title{
Implementation of IOT Based Smart Energy Meter in Oman
}

\author{
Hassan Ali Alajmi \\ Raid Rashid Ali Alsaidi \\ Omar Abdullah Sultan AL-shibli
}

Senthil Ramadoss

\begin{abstract}
Managing the energy efficient and conserving it intelligently for appliances is very much important. On the other side, it may be possible events mistake cause while reading on energy meter, monitoring and keeping track of your electricity consumption for verification is a tedious task today. Our main objective of measuring the power consumption at homes using IOT with raspberry pi during period time, which can be controlled as well monitored through the raspberry pi across the IOT. We used Python programming language to control raspberry pi. It's based on raspbian which is operating system for all models of the raspberry Pi that subject to linux system. As we say before raspberry pi has inputs and we use it for connecting the supply, energy meter and load such as a lamp or Drill. The energy meter is connected to the raspberry pi. This allows user to easily check the energy usage along with the cost charged online using a simple web application connecting to Wi-Fi. Thus, the energy meter monitoring system allows consumer to effectively monitor electricity meter readings and bill amount in an easy way. It presents a low cost and flexible energy meter monitoring system using IOT. In addition, we use camera which is called camera pi. Camera pi takes picture from meter reading and communicates to consumer via email. All information on the energy meter screen will be taken by raspberry pi module. Using this data, the raspberry pi will calculate the bill amount then send to the consumer by email. Finally, this project will help for the proper and accurate reading of the billing process automatically. Also, it enables consumer to save the money for a long time. This technology offers new and exciting opportunity to reduce the work of workers.
\end{abstract}

\section{Introduction}

The internet of things, or IOT, is an arrangement of interrelated registering gadgets, mechanical and advanced machines, items, creatures or individuals that are given extraordinary identifiers (UIDs) and the capacity to exchange. Also there are advantages of IOT like screen their general business forms, improve the client experience, set aside time and cash, improve worker profitability, incorporate and adjust plans of action, settle on better business choices, create more income. The IOT works as IOT biological system comprises of web-empowered brilliant gadgets that utilization inserted processors, sensors and correspondence equipment to gather, send and follow up on information they gain from their surroundings. IOT gadgets share the sensor information they gather by interfacing with an IOT door or other edge gadget where information is either sent to the cloud to be broke down or examined locally. Now and then, these gadgets speak with other related gadgets and follow up on the data they get from each other. The gadgets do the vast majority of the work without human intercession, in spite of the fact that individuals can communicate with the gadgets - for example, to set them up, give them guidelines or access the information On the other side the Raspberry Pi is a minimal effort, Visa estimated PC that attachments into a PC screen or TV, and utilizations a standard console and mouse. It is an able little gadget that empowers individuals of any age to investigate figuring, and to figure out how to program in dialects like Scratch and Python. It can do all that you'd anticipate that a work station should do, from perusing the web and playing top notch video, to making spreadsheets, word- 


\section{Journal of Student Research}

Fourth Middle East College Student Research Conference, Muscat, Sultanate of Oman

handling, and making amusements. Raspberry Pi Work Great, apparently. When purchasing a Raspberry Pi, we get the PC board uncovered without a case, control supply, or even the OS. It is only a PC on a board. Contingent upon the form you get, there can be USB ports, a SD or miniaturized scale SD card per user, a HDMI port, camera sequential interface (CSI), and the GPIO pins referenced previously. There's no hard drive, just locally available RAM for memory. The Raspberry Pi work with IOT as Envision you get an intensity of PC in a crate littler than a charge card in your grasp. So we can utilize this calculation control for making IOT gadget. we can associate sensors to GPIO and since it is a total PC it will get every one of the information... can break down information gathered from sensor on gadget in view of high calculation control and can remain conceal due to little size. Most recent renditions have inbuilt Wi-Fi and Bluetooth so you can send that information on cloud. So it has practically all sort of essential fixings to make IOT gadget. It's a best bundle in little size.

IOT based energy meter is now being the recent research. Every product comes with IOT. If energy meter has IOT then the consumer can have all the information of the energy meter on daily or weekly basis. This monitoring will help the consumer to have control over the consumption. In addition, the labor effort in taking reading in every house will be avoided. Recent papers show that Arduino is also used in smart energy meter design however transmitting needs Wi-Fi component in addition to Arduino board. If raspberry pi is used, then inbuilt Wi-Fi will help to transmit data without any additional component.

In the recent research IOT based energy meter not only identifies the meter values but also the theft. Arduino or raspberry pi can detect the difference between the consumption at the unit and at the branch. Smart energy meter is also deployed in grid for monitoring the power distribution. Microcontroller STM32L152VBT6 is employed along with ZigBee for energy monitoring using smart energy meter. In few papers energy is monitored and sent to the other device or to consumer by SMS. This GSM based service helps the consumer to get instant details about the consumption. The application smart energy meter for smart city has been profoundly used. It has its own benefits by giving accuracy level of $97 \%$ and $25 \%$ low cost in the global market

Digital meter, the ESP8266 module, is used for the web applications for many systems. The IP / TCP protocol is connected between the web application counter and it is used in all practical applications to read the low power meter the cost. Existing portable handheld meters for measuring Kwh is bulky and difficult to handle by the employee who is measuring energy for domestic applications. This IOT integrated energy meter will greatly help to take the readings remotely.

As the bills are paid online this GSM based service will help the consumer to pay the bills in time. They will be aware of the bill in advance so they can manage the payments in time. The implementation cost of IOT based energy meter is economical if the price of camera is reduced with good resolution. However, the dust on the camera or on the energy meter must be taken care. Hence in this paper implementation of IOT based smart energy meter in Oman raspberry pi along with camera is used. Camera has good resolution to pick up the image to process. However, there are many numbers in energy meter apart from the region of interest which must be taken care off.

Survey results for questionnaire in household electrical consumption

In this project we did a questionnaire and included some questions to the consumer and there was a large participation of consumers. 
Journal of Student Research

Fourth Middle East College Student Research Conference, Muscat, Sultanate of Oman

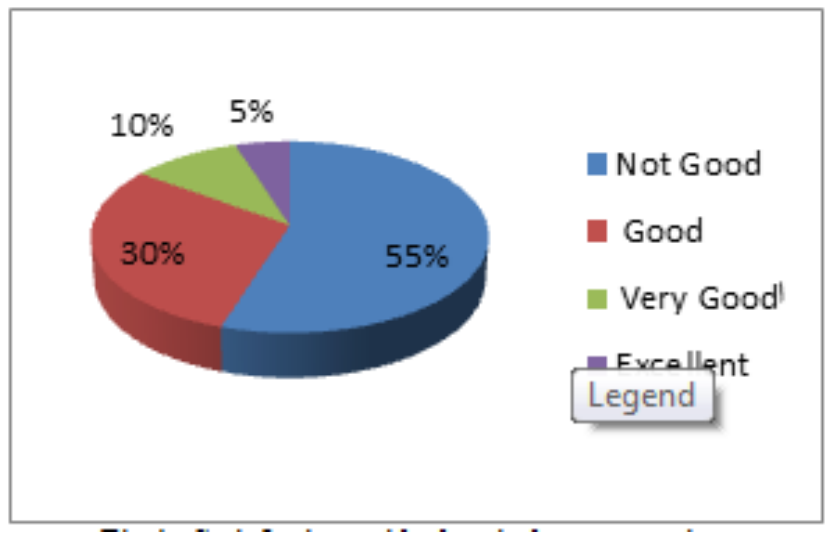

Figure 1. Satisfaction with electrical consumption

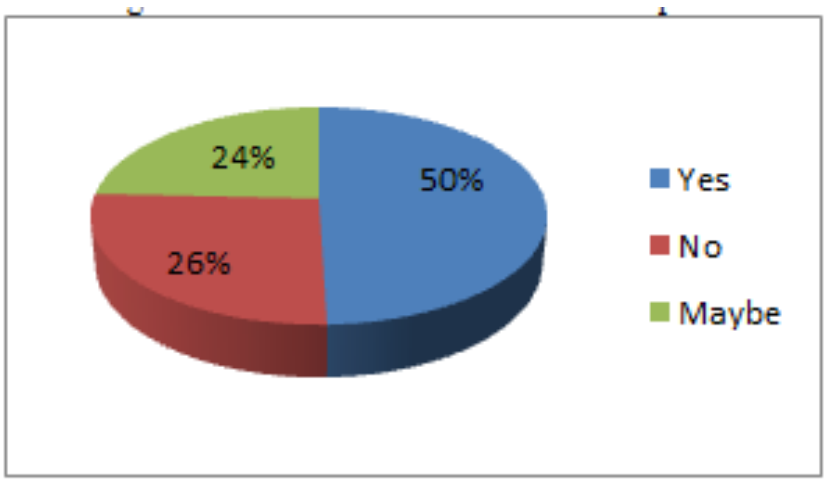

Figure 2. People interest in avoiding electricity consumption

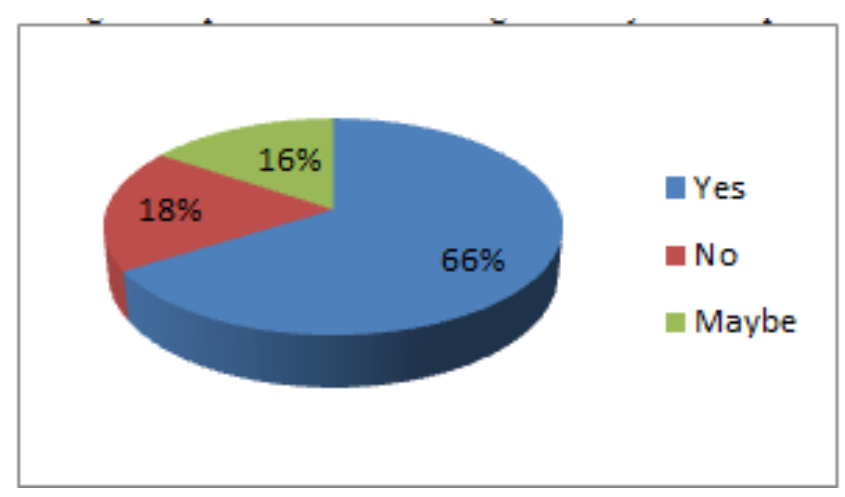

Figure 3. People affected by monthly consumption

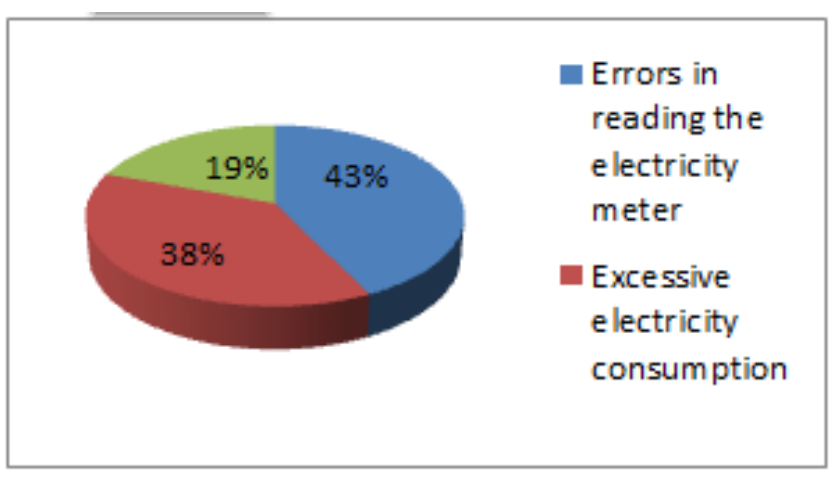

Figure 4. Reason for increase in electricity bill 


\section{Journal of Student Research}

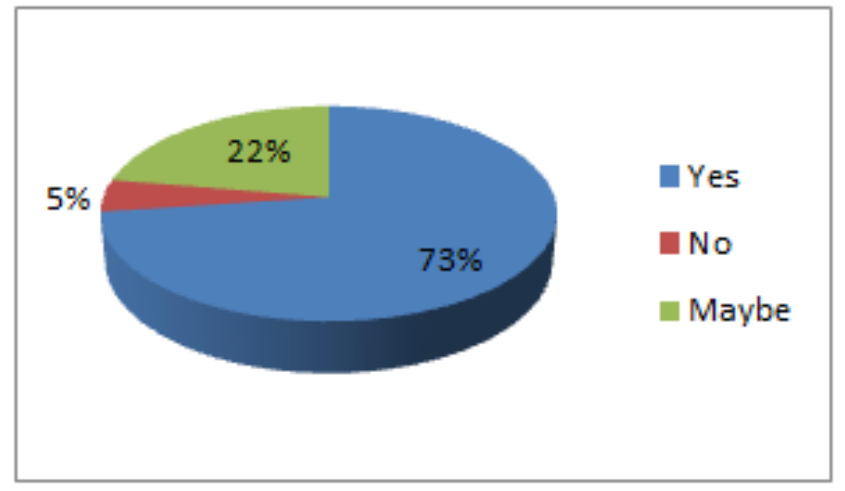

Figure 5. Is there a way to reduce consumption of electricity bills?

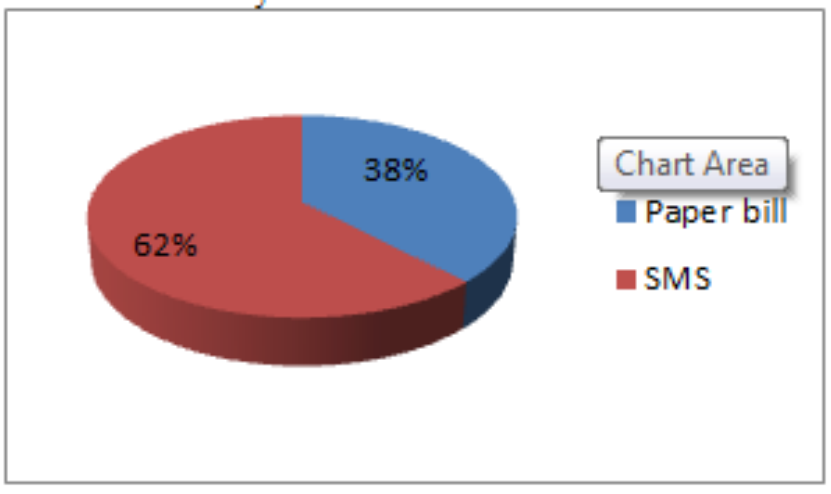

Figure 6. Preference to have electricity bill

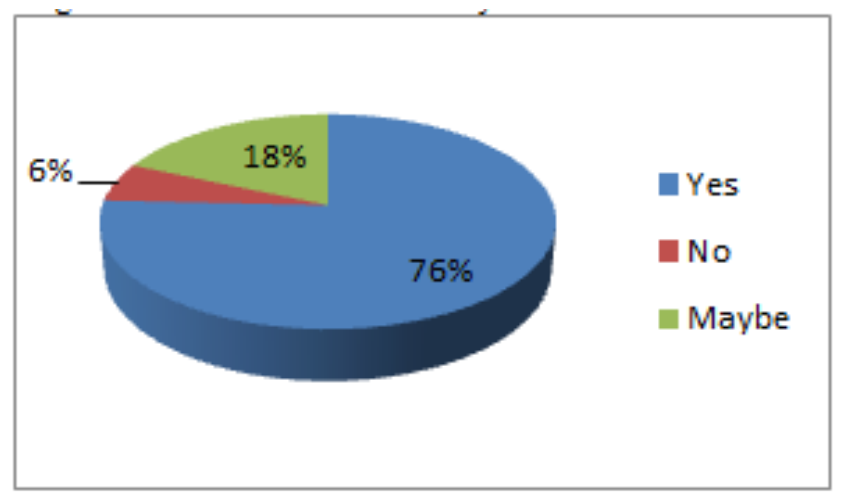

Figure 7. Can reduce consumption if electricity bill known in advance

Fig 1a to $1 \mathrm{f}$ shows the interest the consumer must have more information on electricity bill. Consumer also require methods to avoid consumption and the reason to have increase in electricity bill.

Moreover, consumer wants to have the bill in SMS for easy access. Because if paper bill it may not reach them in time or there is a chance of loosing the paper. If sent in SMS next minute they will be aware of the bill. In addition, if SMS send everyday or weekly basis as per requirement from customer, they can still make good effort in reducing the electricity consumption. Hence, we conclude from the survey that IOT based energy meter implementation in Oman is required for easy access to electricity bill by consumer and make the life easier for consumer.

\section{Working}




\section{Journal of Student Research}

Fourth Middle East College Student Research Conference, Muscat, Sultanate of Oman

Proposed system uses camera to take programmed meter reading. For taking picture camera is set before vitality meter of house. To get digits separate out and to calculate the bill for the month processor has necessary calculations in software. In this paper, Raspberry Pi is utilized on the grounds that it is a kind of minicomputer. We can't introduce Microsoft Windows on it as it utilizes an alternate sort of processor. In the event that we need to, we can utilize the Raspberry Pi to surf the web, send an email and a lot all the more utilizing a word processor. Simple to utilize however incredible, reasonable and hard to break, the Raspberry Pi is the ideal for seeking after PC researchers. After that this bill is send to the server remotely utilizing email and show on LCD for client's reference.

According to meaning of AMR, it permits simple saving through meter reading, more information accuracy; improve billing speed and consumer service. Here camera is put before E-meter as appeared in fig 1. At the point when order is send camera takes the picture. This picture is handled by raspberry pi utilizing form calculation to figure bill and send it utilizing email.

\section{Experimental Procedures}

According to Figure 1 and 2 below firstly picture of meter is taken utilizing camera. Process this picture with raspberry pi utilizing shape calculation. Form calculation functions as pursues, the thought behind the square following calculation is extremely basic; this could be credited to the way that the calculation was one of the main endeavors to separate the shape of a double example. Given a computerized example for example a gathering of dark pixels, on a foundation of white pixels for example a lattice; find a dark pixel and announce it as your "begin" pixel. (Finding a "begin" pixel should be possible in various ways; we'll begin at the base left corner of the matrix, examine every section of pixels from the base going upwards - beginning from the furthest left segment and continuing to one side until we experience a dark pixel. Pronounce that pixel as our "begin" pixel. Presently, envision that you are a bug (ladybird) remaining on the begin pixel as in fig underneath. So as to separate the form of the example, you need to do the accompanying: each time you wind up remaining on a dark pixel, turn left, and each time you end up remaining on a white pixel, turn right, until you encounter the start pixel again. The black pixels are the contour of the pattern. 


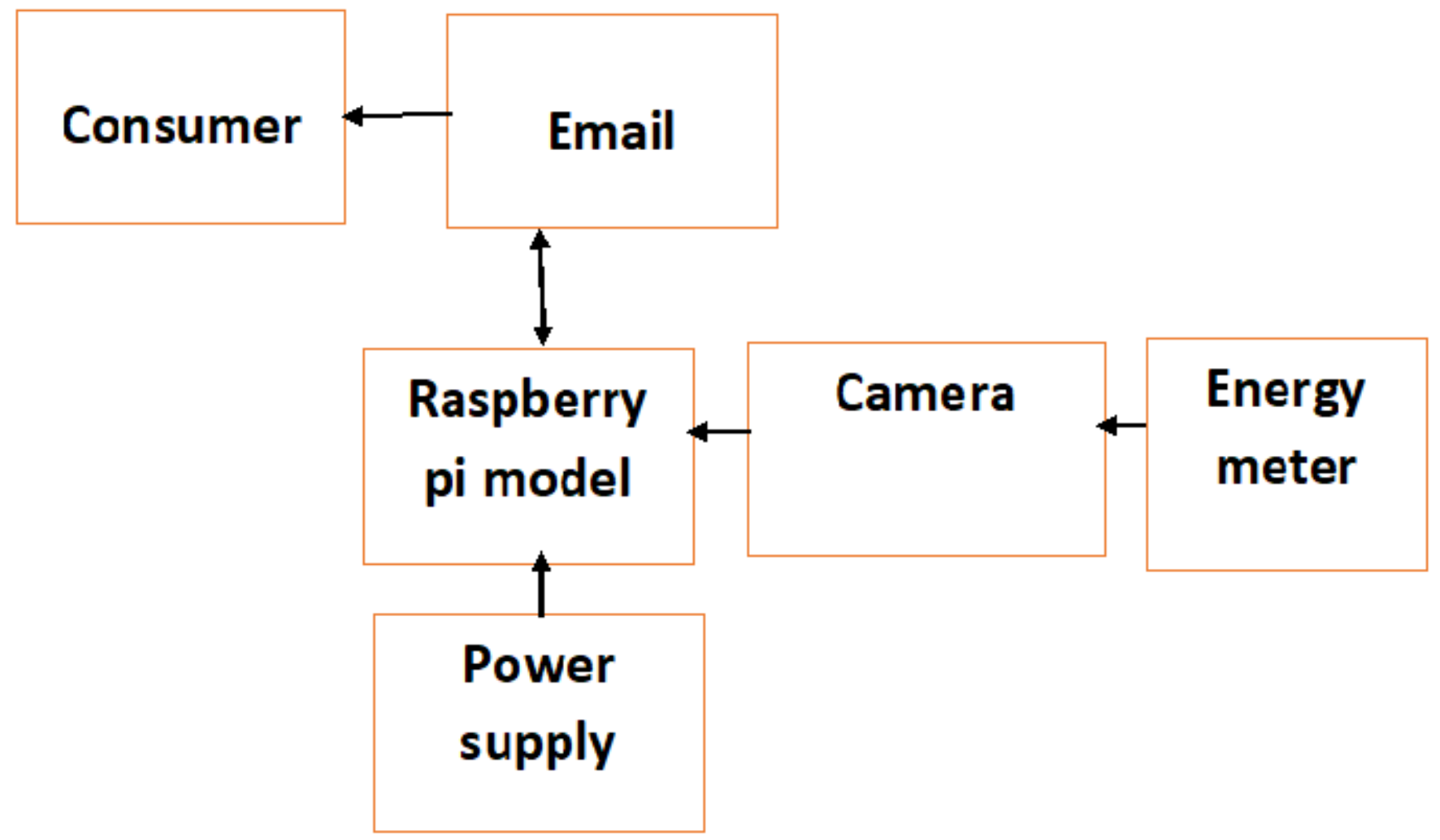

Figure 8. The Block Diagram of IOT based Energy Meter

Figure 9. Raspberry pi based IOT

\section{Results}

After the account you will receive a message to the consumer by email that carries his daily consumption

\section{Discussion}

The consumer knows the value of his daily consumption with this model. Consumer will reduce his consumption as he knows the monthly bill in advance. Consumer can have better control over the expenditure and he can take preventive action.

\section{Conclusion}

There are many consumers who is facing problem of energy consumption and it is can be annoying in some situations. Our paper is solution to above as it is used to calculate the energy consumption of the household automatically.

Energy is an essential one for household, industries, agriculture and many. Managing the energy efficiency and conserving it intelligently for appliances is very much important.

However, since camera is used for capturing the image of energy meter raspberry pi will be the best choice for calculating the electricity bill. 


\section{Journal of Student Research}

Fourth Middle East College Student Research Conference, Muscat, Sultanate of Oman

Finally, this paper provides proper and accurate reading of the billing process automatically. Also, it enables consumer to save the money consistently. This technology offers new and exciting opportunity to reduce the work of workers in electricity board.

\section{Acknowledgements}

we acknowledge Dr. Salim IT Department Shinas College of Technology for helping us in coding the raspberry pi. Special thanks to Dr. Ahmed Abdullah Al-Balushi HOD Engineering and Mr. B. Kalyan Kumar HOS for all the support in completing related project work.

\section{References}

Depuru, S. S. S. R., Wang, L., Devabhaktuni, V., \& Gudi, N. (2011, March). Smart meters for power grid-Challenges, issues, advantages and status. In 2011 IEEE/PES Power Systems Conference and Exposition (pp. 1-7).

Gubbi, J., Buyya, R., Marusic, S., \& Palaniswami, M. (2013). Internet of Things (IoT): A vision, architectural elements, and future directions. Future generation computer systems, 29(7), $. .1645-1660$

Zhao, C. W., Jegatheesan, J., \& Loon, S. C. (2015). Exploring iot application using raspberry pi. International Journal of Computer Networks and Applications, 2(1), 27-34.

Fouzia, \& Fouzia. (2019, July 26). Raspberry Pi Technology, Working and Its Applications.

Hlaing, W., Thepphaeng, S., Nontaboot, V., Tangsunantham, N., Sangsuwan, T., \& Pira, C. (2017, March). Implementation of WiFi-based single phase smart meter for Internet of Things (IoT). In 2017 International Electrical Engineering Congress (iEECON) (pp. 1-4). IEEE..

Rahman, M. M., Islam, M. O., \& Salakin, M. S. (2015, May). Arduino and GSM based smart energy meter for advanced metering and billing system. In 2015 International Conference on Electrical Engineering and Information Communication Technology (ICEEICT) (pp. 1-6). IEEE.

Jain, S., Kumar, V., Paventhan, A., Chinnaiyan, V. K., Arnachalam, V., \& Pradish, M. (2014, March). Survey on smart grid technologies-smart metering, IoT and EMS. In 2014 IEEE Students' Conference on Electrical, Electronics and Computer science (pp. 1-6). IEEE.

Morello, R., De Capua, C., Fulco, G., \& Mukhopadhyay, S. C. (2017). A smart power meter to monitor energy flow in smart grids: The role of advanced sensing and IoT in the electric grid of the future. IEEE Sensors Journal, 17(23), 7828-7837.. 